\title{
Epidural Anestezi ile Vajinal Doğum Yapan ve Anestezisiz Vajinal Doğum Yapan Primipar Annelerde ilk 24 Saatte Etkili Emzirmenin Değerlendirilmesi*
}

\author{
The Evaluation of Breastfeeding During The First 24 Hours in Primiparous Mothers Who Had a Vaginal Birth With \\ or Without Epidural Anaesthesia
}

Illknur M. Gönenç'1 Gülșen Vural²

Ankara Üniversitesi Sağlık Bilimleri Fakültesi Ebelik Bölümü Sanko Üniveristesi Sağlık Bilimleri Fakültesi Hemşirelik Bölümu Makale 20-23 Kasım tarihleri arasında düzenlenen 3. Ulusal 2. diri olarak sunulmus ve birincilik ödülü almıștır.
Geliș tarihi : 5.06.2015 • Kabul tarihi: 25.08.2015

\section{İletișim}

Yrd. Doç. Dr. İlknur M. GÖNENÇ

Tel: 3191450/1131

E-posta: imgonenc@gmail.com

Ankara Üniversitesi Sağlık Bilimleri Fakültesi Ebelik Bölümü Sükriye Ma. Plevne Cad. Aktaș Kavșağı No:5

06340 Altındağ/Ankara

Amaç: Araștırma epidural anestezi ve anestezisiz vajinal doğum yapan primipar kadınların ilk 24 saatte etkili emzirmelerinin değerlendirilmesi amacıyla karșılaștırmalı ve betimsel olarak yapıldı.

Gereç ve Yöntem: Araștırmanın örneklemini, anestezisiz doğum yapmıș 40 anne ile epidural anestezi ile doğum yapan 40 anne olușturdu. Verilerin toplanmasında veri toplama formu ve LATCH Emzir me Tanılama Ölçüm Aracı kullanıldı. Her anne doğumdan sonra ilk 24 saatte 3 kez değerlendirildi. Verilerin değerlendirilmesinde yüzdelik hesaplanması, Pearson ki-kare, Mann- Whitney U ve Fisher's Exact Testleri kullanıldı.

Bulgular: Annelerin \%60'ı ilk 30 dakika içinde bebeğini emziremedi. Emzirmeye bașlama zamanı açısından iki grup arasında istatistiksel olarak önemli bir fark tespit edilmedi $(p>0,05)$. Bebeklerin uyku hali, emmeye ait refleksleri, APGAR skorları ve LATCH puanları açısından iki grup arasında istatistiksel olarak önemli bir fark bulunmadı $(p>0,05)$. 24. saatte emme sırasında bebeğin șakaklarında hareket olma durumunun anestezisiz olan grupta daha yüksek olduğu bulundu $(p<0,05)$. Epidural grubunda 12 . ve 24 . saatlerde meme ucunda ağrı șikayeti yüksek bulundu $(p<0,05)$. Çalıșmamızda epidural uygulanan grupta 'sütüm yok, meme ucumu sıktığımda süt gelmiyor' șikayeti daha yüksek oranda ifade edildi.

Sonuçlar: Araștırma sonuçlarımıza göre, epidural anestezi bebeğin emme reflekslerini ve emmesini olumsuz etkilemeden süt salınımını geciktirebilmektedir.

Anahtar Sözcükler: Anne Sütü, Emzirme, Epidural Anestezi

Aim: The purpose of the study was to evaluate the breastfeeding during the first 24 hours in nulliparous mothers who had a vaginal birth with or without epidural anaesthesia.

Material and Method: Study cohorts consited of 40 mothers who had vaginal birth with epidural anesthesia and 40 mothers who had birth without anesthesia. A data collection form and the LATCH Breast Feeding Point System were used. Each mother was evaluated three times in a 24-hour period in the hospital.

Results: Sixty percent of mothers in each group did not breastfeed within the first 30 minutes. There was no significant difference between two groups for the time of beginning to feed the baby $(p>0,05)$. There were no significant difference between baby's sleeping situation and reflexes of sucking $(p>0,05)$. No differences were diagnosed by first and fifth minutes APGAR scores $(p>0,05)$. No meaningful differences were observed in 6 th 12 th and 24 th hours by LATCH points. At $24^{\text {th }}$ hour, baby's temple moving was higher in without anesthesia group $(p<0,05)$. In epidural group, $12^{\text {th }}$ and $24^{\text {th }}$ hours nipple-ache complaints were higher $(p<0,05)$. In our research there was no meaningful difference of situation at sufficiency of milk. Complaints of milk's insufficient quantity was higher in mother with epidural group.

Conclusion: Epidural anaesthesia does not effect babies sucking reflexes, but, complaints of insufficient milk were more common in the epidural group and delays milk secretion.

Key Words: Human Milk, Breastfeeding, Epidural Anesthesia

Büyüme ve gelișmenin en hızlı olduğu bebeklik döneminde yeterli ve dengeli beslenmeyi sağlayan en uygun besin anne sütüdür (1). Anne sütünün anne ve bebek sağlığ1 üzerine kısa ve uzun dönemde sayısız faydaları olmasina rağmen ülkemizde emzirilen çocuklarin sadece \% 49.9'u doğumdan sonraki bir saat içinde emzirilmeye başlamakta ve \% 28.8'i doğumdan sonraki ilk 24 saatte hiç emzirilmemektedir (2). Erken dönemde emzirmeye 
başlamayı etkileyen pek çok faktör vardır. Bu faktörlerden birisi doğum süresince kullanılan analjezik ve anestezik ilaçlardır $(1,3,4)$. Dünyada ve ülkemizde hızla kullanımı artan ve doğum ağrisinın rahatlatılmasında çok etkili bir yöntem olan epidural anestezinin emzirmeye başlamaya ve emzirme sürecine olumsuz etkileri olduğu belirtilmektedir (5-9). Epidural anestezide kullanılan ilaçların, plesanta aracılı ile fetüse geçtiği ve bu durumun doğumdan sonra bebeğin reflekslerini etkilediği düşünülmektedir (10). Literatürde epidural anestezi kullanımının yenidoğanın nörolojik davranışlarını ve etkin emzirmeyi etkilemediğini belirten farklı çalışmalar da bulunmaktadır $(11,12)$. Doğumda kullanilan epidural anestezinin yenidoğanın davranıș skorunu etkilemesinin yanında emzirmeye erken dönemde başlamayı ve emzirme sürecini de etkilediği düşünülmektedir (11). Epidural anestezinin bir başka etkisinin de süt salınımı üzerine olabileceği düşünülmektedir. Yapılan çalışmalara göre, doğumda kullanılan epidural anestezinin oksitosin salınımını engellediği, bu nedenle süt salınımını geciktirdiği belirtilmektedir $(13,14)$.

Annelerin doğumdan sonra emzirmeye teşvik edildiği ülkemizde ise epidural anestezinin emzirme üzerine etkisini araştıran bir çalışmaya ulaşılamamıştır. Epidural anestezinin emzirmeye olan etkisinin araştırılmasının emzirmenin başlatılmasinda önemli bir bilgi kaynağ1 olacağ1 ve literatüre de katk1 sağlayacağ1 düşünülmüştür. $\mathrm{Bu}$ araştırma epidural anestezi ve anestezisiz vajinal doğum yapan primipar kadınlarda ilk 24 saatte etkili emzirmenin değerlendirilmesi amacıyla yapilmıştır.

\section{GEREÇ VE YÖNTEM}

$\mathrm{Bu}$ araştırma tanımlayıcı ve karşılaştırmalı bir çalışma olarak yapıldı. Araştırma, Ankara ilinde bulunan Dr. Zekai Tahir Burak Kadın Sağllğ1 Eğitim ve Araştırma Hastanesi'nde yürütüldü. Araştırmanın evrenini bir yıl içinde vajinal doğum yapan ve özel servislerde yatan anneler oluşturdu.

Araştırma kapsamına miadında, doğum tartıs1 2500-4000 g, 1. ve 5. dakika APGAR skoru 7 ve üzeri olan, her- hangi bir hastalığ1 ve konjenital anomalisi olmayan yenidoğanlar ile bilinen herhangi bir psikolojik veya fiziksel sorunu olmayan, 18-35 yaş arasın$\mathrm{da}$, en az ilkokul mezunu olan ve bebeğini emzirmeyi isteyen primipar sağlıklı anneler alındı. Araştırmanın yapıldığı dönemde (Mart 2008- Ocak 2009) epidural anestezi ile vajinal doğum yapan ve araştırma kriterlerine uyan tüm anneler araştırma kapsamına alındı. Çalışmanın yapıldığı tarihler arasında toplam 89 anne epidural anestezi ile vajinal doğum yapmış olup bunların 40'inin yukarida belirtilen kriterlere uyduğu belirlendi. Benzer özelliklere sahip anestezisiz doğum yapan 40 anne de çalışmaya dahil edildi. Araştırmanın gücünü belirlemek için GPOWER paket programı kullanılmış olup değerlendirmeler bu çerçevede ele alındı. Araştırmanın örneklemine 0,72 power ve 0,05 güven düzeyinde anestezisiz vajinal doğum yapmiş 40 anne ile epidural anestezi ile vajinal doğum yapan 40 anne alındı.

Verilerin toplanmasında araştırmacı tarafindan literatür (1-3,15-18) bilgisinden yararlanılarak geliştirilen ve 5 uzman görüşü alınan veri toplama formu ve LATCH Emzirme Puanlama Sistemi (Breastfeeding Charting System) kullanıldı. Veri toplama formunun birinci bölümde anneye ait bilgiler (32 soru), ikinci bölümde bebeğe ait bilgiler (8 soru), üçüncü bölümde anne sütünün önemi ve emzirmeye istekliliğini sorgulayan sorular (5 soru), dördüncü bölümde de ilk 24 saatte emzirmeyi değerlendirmeyi amaçlayan sorular yer almaktadır.

LATCH Emzirme Tanılama Ölçüm Arac1 (Breastfeeding Charting System), annelerin emzirme tutumlarinı değerlendirmek amaciyla Jensen, Wallace, Kelsay tarafindan 1994 yilinda geliştirilen (19), 2001 y1lında Yenal ve Okumuş tarafindan ülkemizde geçerlilik ve güvenilirlik çalışmaları yapılan bir ölçektir (20). Yenal ve Okumuş’un yaptığı çalışmada Cronbach's Alfa değerleri 1. emzirme için 0.96, 2. emzirme için 0.94 olarak belirlenmiştir (20). LATCH Emzirme Tanilama Ölçüm Aracı etkili emzirmenin değerlendirilmesinde kullanılan 5 kriterden oluşmaktadır (19-21). Bu kriter- ler; memeyi tutma (Latch on breast), bebeğin yutma hareketinin görülmesi (Audiple Swallowing), annenin emzirme sonrası meme başının tipi, (Type Of Nipple), annenin meme ucu ve meme ucuna ilişkin rahatlığ1 (Comfort of Breast, Nipple) ve annenin bebeği tutuş pozisyonudur (Hold/ Help). Beş kriter için ayrı değerlendirme yapilmıș ve $0-2$ puan arasında bir puan verilmiştir. Her kriter için verilen puanlar toplanmış ve emzirme değerlendirilmiștir. Puanlama sonrası alınabilecek en yüksek puan 10 'dur. Toplam puanın 10'nun altında olması annenin emzirme konusunda desteğe ihtiyacı olduğunu göstermektedir (1921).

Çalışmada ilk 24 saatteki emzirme durumu değerlendirileceği için ölçümlerin hepsi doğumdan sonraki ilk 24 saatte yapıldı. Emzirme, doğumdan sonraki 6.saat, 12.saat, 24.saat olmak üzere toplam $3 \mathrm{kez}$ değerlendirildi. Çalışmacının bulunmadığı saatlerde değerlendirmelerin yapılabilmesi için, çalışmanın yürütüldüğü servislerde gece çalışan 6 hemşire araştırmaya başlamadan önce, görüşme formu ve LATCH Emzirme Tanılama Ölçüm Aracı hakkında araştırmacı tarafindan eğitildi. Klinik hemşireleri tarafindan yapılan bu değerlendirmeler, anneden alınan bilgiler ışı̆̆ında çalışmacı tarafindan tekrar değerlendirildi. İki değerlendirme sonucunun birbirine paralel olduğu görüldü. Emzirme davranışı, bir emzirmenin başlangıcından bitişine kadar veri toplama formunda ve LATCH Emzirme Tanilama Ölçüm Aracı'nda bulunan kriterler açsindan gözlendi.

Araştırmada elde edilen veriler bilgisayar ortamında bir istatistik paket progra$\mathrm{m}$ kullanılarak değerlendirildi. Verilerin değerlendirilmesinde, yüzdelik hesaplamas1, Pearson Chi-Square, Mann-Whitney U ve Fishers Exact önemlilik testleri kullanıldı.

Araştırmanın yapılabilmesi için ilgili hastanenin Eğitim Planlama ve Koordinasyon Kurulunun kararı ile yazılı izin alındı. Ayrıca araştırma kapsamına alınan annelere araştırmanın amacı açıklanarak yazılı onamları alındı. Araştırma süresince kadınların sorular1 doğrultusunda bilgi ve danışmanlık verildi. 


\section{BULGULAR}

Araştırmada gruplarda yer alan annelerin demografik özellikleri benzer dağılım göstermekte olup, Tablo 1'de verilmiştir.

Epidural uygulanan grupta bulunan annelerin \%90'ninin, uygulanmayan grupta bulunan annelerin \%75'nin gebeliği planlıdır. Epidural uygulanan grupta bulunan annelerin \% 67.5\%i, epidural uygulanmayan grupta bulunan annelerin \% 55'i emzirme eğitimi almamıştır.

Epidural uygulanan ve uygulanmayan grupta bulunan bebeklerin 1. dakika APGAR skoru ortalaması 7, 5. dakika APGAR skoru ortalamas1 9'dur. Bebeklerin 1 ve 5 . dakikadaki APGAR skorları açısından iki grup arasında istatistiksel olarak önemli bir farklılık bulunmamaktadır ( $p>0,05)$. Epidural uygulanan grupta bulunan annelerin bebeklerinin $\% 85$ 'i, epidural uygulanmayan grupta bulunan annelerin bebeklerinin \% 97.5'i doğumdan hemen sonra ağlamıştır. Bebeklerin ağlama durumları açısından iki grup arasindaki fark istatistiksel olarak önemsizdir $(\mathrm{p}>0,05)$. Epidural uygulanan grupta bulunan bebeklerin \%31.6's1, epidural uygulanmayan gruptaki bebeklerin \%47.4'ü anneleri ile ilk 30 dakika içinde temas etmemiştir. Anne ile ilk temas zamanı açısından iki grup arasında istatistiksel olarak önemli bir farklılık bulunmamaktadır ( $\mathrm{p}>0,05)$.
Her iki grupta bulunan annelerin \%60'1 ilk 30 dakika içinde emzirmeye başlayamamıştır. İlk emzirmeyi başlatmada hemşire/ebelerin oranlarının yüksek olduğu (Epidural uygulanan grupta $\%$, epidural uygulanmayan grupta $\% 75$ ) bulunmuştur. İlk 6. saat içinde bebeklerin epidural uygulanan grupta $\% 92.5$ 'inin, epidural uygulanmayan grupta \%95'inin arama ve emme refleksi bulunmaktadır. Emmeye ait refleksler (arama refleksi ve emme refleksi) açısından karşılaştırıldığında iki grup arasındaki farkin 6., 12. ve 24 . saatlerdeki gözlemlerde istatistiksel olarak önemsiz olduğu belirlenmiştir $(p>0,05)$. 6. saatte emzirme sirasinda yapılan gözlemde epidural uygulanan gruptaki bebeklerin \%28.2'sinde, epidural uygulanmayan gruptaki bebeklerin \%30.8'inde uyku hali gözlenmiştir. Bebeklerin uyku hali açısından 6.,12.,24. saatlerde iki grup arasinda istatistiksel olarak önemli bir fark bulunmamaktadır ( $>>0,05)$.

Altıncı saatteki ölçümde epidural uygulanan gruptaki bebeklerin \%5.3'ünde, epidural uygulanmayan gruptaki bebeklerin \% 7.5'inde yutkunma sesi duyulmuştur. 12. saatteki oranlar sırasiyla \%13.2 ve \% 12.5, 24. saatteki ölçümde ise \%13.2 ve \%25.6'dır. İki grup arasinda 6. 12 . ve 24 . saatlerde yapilan gözlemlerde istatistiksel olarak önemli bir farklilık tespit edilmemiştir ( $\mathrm{p}>0,05)$.

Emzirme sırasında bebeklerin şakak hareketi incelendiğinde, 6. saatte epidural uygulanan gruptaki bebeklerin \%7.5'inde, uygulanmayan gruptaki

Tablo 1: Annelerin Demografik Özeliklerinin Gruplara Göre Dağılımı

\begin{tabular}{|c|c|c|c|c|c|c|}
\hline \multirow{2}{*}{$\begin{array}{c}\text { Annelerin Bazı } \\
\text { Demografik } \\
\text { Özellikleri }\end{array}$} & \multicolumn{2}{|c|}{$\begin{array}{l}\text { Epidural Uygulanmayan } \\
\qquad(n=40)\end{array}$} & \multicolumn{2}{|c|}{$\begin{array}{c}\text { Epidural } \\
\text { Uygulanan }(n=40)\end{array}$} & \multicolumn{2}{|c|}{ Toplam $(n=80)$} \\
\hline & $\mathbf{n}$ & $\%$ & $\mathbf{n}$ & $\%$ & $\mathbf{n}$ & $\%$ \\
\hline \multicolumn{7}{|l|}{ Yaș } \\
\hline $18-23$ & 16 & 40,0 & 10 & 25,0 & 26 & 32,5 \\
\hline $24-29$ & 14 & 35,0 & 17 & 42,5 & 31 & 38,75 \\
\hline $30-35$ & 10 & 25,0 & 13 & 32,5 & 23 & 28,75 \\
\hline \multicolumn{7}{|l|}{ Eğitim Durumu* } \\
\hline illkokul & 7 & 17,5 & 0 & 0,0 & 7 & 8,75 \\
\hline Ortaokul & 6 & 15,0 & 5 & 12,5 & 11 & 13,75 \\
\hline Lise & 17 & 42,5 & 14 & 35,0 & 31 & 38,75 \\
\hline Lisans ve üzeri & 10 & 25,0 & 21 & 52,5 & 31 & 38,75 \\
\hline \multicolumn{7}{|l|}{ Çalıșma Durumu } \\
\hline Çalıșmıyor & 29 & 72,5 & 21 & 52,5 & 50 & 62,5 \\
\hline Çalıșıyor & 11 & 37.5 & 19 & 47.5 & 30 & 37.5 \\
\hline Toplam & 40 & 100,0 & 40 & 100,0 & 80 & 100,0 \\
\hline
\end{tabular}

bebeklerin \% 15'inde şakaklarda hareket vardır. On ikinci saatteki ölçümde epidural uygulanan ve uygulanmayan grupta bu oranlar sirasiyla $\% 12.5$ ve $\% 25$, yirmi dördüncü saatte ise $\% 15$ ve $\% 41$ 'dir. İki grup arasinda 6. ve 12. saatte yapilan gözlemlerde istatistiksel fark bulunmazken, 24. saatte emme sırasında bebeğin şakaklarında hareket olma durumunun epidural uygulanmayan grupta istatistiksel olarak anlamlı şekilde yüksek olduğu bulunmuştur $(\mathrm{p}<0,05)$.

Altınc1 saatte her iki grupta bulunan bebeklerin \%65'i kesik-kesik emmektedir. Uzun-Yavaş emen bebeklerin oranı ise epidural uygulanan grupta $\% 10$, uygulanmayan grupta $\% 22.5$ 'dir. 12. saatteki bu oranlar s1rasiyla $\% 32.5$ ve $\% 70,24$ saatteki izlemde ise $\% 40$ ve $\% 67.5$ ' dir.

Epidural uygulanan grupta bulunan annelerin $\% 15$ 'inde 6 . saatte, $\% 55$ 'inde 12.saatte, $\% 57.5$ 'inde 24 . saatte süt salınımı belirtilerinden (memelerde karıncalanma, uterusta ağri, memelerden süt akması, kanamada artış) en az bir tanesi mevcuttur. Epidural uygulanmayan grupta bulunan annelerin ise $\% 25$ 'inde 6 . saatte, $\% 55$ 'inde 12.saatte, $\% 57.5$ 'inde 24 . saatte süt salınımı belirtilerinden en az bir tanesi mevcuttur. İki grup arasinda 6, 12 ve 24. saatlerdeki süt salınımı belirtileri açısından fark istatistiksel olarak önemsizdir ( $\mathrm{p}>0,05)$.

Epidural uygulanan grupta bulunan annelerin LATCH puan ortalaması Tablo 2'de verilmiştir. İki grup arasında 6., 12. ve 24. saatlerdeki LATCH puan ortalaması açısından istatistiksel olarak önemli bir farklılık belirlenmemiştir ( $\mathrm{p}>0,05$; Tablo 2).

Epidural uygulanan grupta bulunan annelerin $\% 17.5$ 'inde 6 . saatte, \%30'unda 12.saatte, $\% 35$ inde 24 . saatte meme ucunda kızarıklık olduğu tespit edilmiştir. Bu oranlar epidural uygulanmayan grupta ise sirasiyla \%15'inde, $\% 17$ ve $\% 22.5$ ' dur. Meme başında 6, 12 ve 24 . saatlerdeki kızarıklık olma durumu ile epidural anestezi kullant$\mathrm{m} 1$ arasında istatistiksel olarak anlamlı bir ilişki tespit edilmemiştir ( $p>0,05)$. 
Tablo 2: Grupların LATCH Puanlarına Göre Dağılımı

\begin{tabular}{|c|c|c|c|c|c|c|c|c|c|c|c|c|c|c|c|c|}
\hline \multirow{2}{*}{ LATCH Puanı } & \multicolumn{5}{|c|}{$\begin{array}{l}\text { Epidural Uygulanmayan } \\
\qquad(n=40)\end{array}$} & \multicolumn{5}{|c|}{$\begin{array}{l}\text { Epidural Uygulanan } \\
(n=40)\end{array}$} & \multicolumn{4}{|c|}{ Toplam $(n=80)$} & \multicolumn{2}{|c|}{ Önemlilik Testi } \\
\hline & Mean & Median & Min & Max & ss. & Mean & Median & Min & Max & ss & Mean & Median & Min & Max & $\begin{array}{c}\text { Mann- } \\
\text { Whitney U }\end{array}$ & $p$ \\
\hline 6. saat & 7,385 & 7 & 4 & 10 & 44,19 & 6,900 & 7 & 5 & 9 & 35,91 & 7,139 & 7 & 4 & 10 & 616,5 & 0,100 \\
\hline 12. saat & 8,308 & 9 & 4 & 10 & 42,90 & 8,050 & 8 & 5 & 10 & 37,18 & 8,177 & 9 & 4 & 10 & 667 & 0,237 \\
\hline 24. saat & 8,718 & 9 & 5 & 10 & 44,60 & 8,350 & 8,5 & 5 & 10 & 35,51 & 8,532 & 9 & 5 & 10 & 600,5 & 0,054 \\
\hline
\end{tabular}

Epidural uygulanan grupta bulunan annelerin \%15'i 6.saatte, \%25'i 12. ve 24 . saatlerde, uygulanmayan grupta bulunan annelerin ise $\% 2.5$ i 6. saatte, $\% 5 \%$ 12.saatte ve 24.saatlerde meme ucunda ağr1 şikayeti olduğunu belirtmişlerdir. Meme başında 6. saatte ağn olma durumu ile epidural anestezi kullanımı arasında istatistiksel olarak önemli bir ilişki tespit edilmemişken ( $p>0,05), 12$. ve 24 . saatlerde epidural uygulanan grupta meme ucunda ağn ifade eden annelerin istatistiksel olarak önemli oranda yüksek olduğu tespit edilmiştir $(\mathrm{p}<0,05)$.

Annelerin sütlerini yeterli görme durumları açısından 6., 12., 24. saatlerde gruplar arasında fark olmadığı belirlenmiştir (Tablo 3). Annelerin sütlerini yeterli görmemelerinin en önemli nedenini; epidural uygulanan grupta bulunan anneler 'sütüm yok, meme ucumu sıktı̆̆ımda süt gelmiyor' (\%64.7) şeklinde ifade ederken, epidural uygulanmayan grupta bulunan anneler 'yeterli olup olmadığını anlayamiyorum' (\%27.7) şeklinde ifade etmişlerdir.

Her iki grupta bulunan bebeklerin $\% 67.5$ 'i ilk 24 saatte kusmamıştır. Bebeklerin boşaltım alışkanlıkları açısindan incelendiğinde, her iki grupta bulunan bebeklerin tamamı 24 saat

Tablo.3: Annelerin Bebekleri İçin Sütlerini Yeterli Görme Durumunun Gruplara Göre Dağılımı

\begin{tabular}{|c|c|c|c|c|c|c|c|c|c|}
\hline \multirow[t]{2}{*}{ Sütün Yeterliliği } & \multicolumn{2}{|c|}{$\begin{array}{c}\text { Epidural } \\
\text { Uygulanmaya } \\
(n=40)\end{array}$} & \multicolumn{2}{|c|}{$\begin{array}{l}\text { Epidural Uygulanan } \\
\qquad(\mathrm{n}=\mathbf{4 0 )}\end{array}$} & \multicolumn{2}{|c|}{ Toplam $(n=80)$} & \multicolumn{3}{|c|}{ Önemlilik Testi } \\
\hline & $\mathbf{n}$ & $\%$ & $\mathbf{n}$ & $\%$ & $\mathbf{n}$ & $\%$ & $\mathbf{X}^{2}$ & sd & $\mathbf{p}$ \\
\hline \multicolumn{10}{|l|}{ 6.saatte } \\
\hline Yeterli & 22 & 55 & 23 & 57,5 & 45 & 56,25 & \multirow{2}{*}{0,05} & \multirow{2}{*}{1} & \multirow{2}{*}{0,821} \\
\hline Yeterli Değil & 18 & 45 & 17 & 42,5 & 35 & 43,75 & & & \\
\hline \multicolumn{10}{|l|}{ 12.saatte } \\
\hline Yeterli & 33 & 82,5 & 29 & 72,5 & 62 & 77,5 & \multirow{2}{*}{1,146} & \multirow{2}{*}{1} & \multirow{2}{*}{0,284} \\
\hline Yeterli Değil & 7 & 17,5 & 11 & 27,5 & 18 & 22,5 & & & \\
\hline \multicolumn{10}{|l|}{ 24.saatte } \\
\hline Yeterli & 35 & 87,5 & 35 & 87,5 & 70 & 87,5 & \multirow{2}{*}{0} & \multirow{2}{*}{1} & \multirow{2}{*}{1} \\
\hline Yeterli Değil & 5 & 12,5 & 5 & 12,5 & 10 & 12,5 & & & \\
\hline
\end{tabular}

içinde en az 1 kere idrar ve gaita yapmıştır. Epidural uygulanan grupta bulunan bebeklerin \%65'i, epidural uygulanmayan grupta bulunan bebeklerin ise \%62.5'i ilk 24 saatte toplam 4-6 kez idrar yapmıştır. Her iki grupta bulunan bebeklerin \%80'i 1-3 kez gaita yapmiştir.

\section{TARTIȘMA}

Anne sütü ile beslenmeyi etkileyen faktörlerden biri olan epidural anestezinin emzirmeye olan etkisinin araşt1rılması yaşama sağlıklı başlama açısından çok önemlidir.

Yenidoğanın sağlık durumu da emzirmeyi etkileyen faktörlerdendir. Bu çalışmada epidural anestezi uygulanmış ve uygulanmamış annelerin bebeklerinin 1. ve 5. dakika APGAR skorları açısindan istatistiksel olarak önemli bir farklilık tespit edilmemiştir. Bu çalışmaya benzer șekilde Zuppa ve arkadaşları (2014) epidural kullanımının 1. ve 5. dakika APGAR skorunu etkilemediğini belirtmişlerdir (22). Çalışma bulgusu literatür ile benzerlik göstermekte olup, yapılan pek çok çalışmanın sonuçları bu çalışma ile paralel bulunmuştur (23-25).

Çalışmaya katılan annelerin tamamı ilk 24 saatte bebeğini emzirmiş olmasına rağmen, her iki grupta bulunan annelerin \%60'1 ilk 30 dakika içinde emzirmeyi başlatamamışlardır. Emzirmeye başlama zamanı açısından iki grup arasinda istatistiksel olarak önemli bir fark belirlenmemiștir. Mauri ve arkadaşlarının yaptıkları çalışmada (2015), benzer şekilde iki grup arasında emzirmeye başlama zamanı açısından bir fark olmadığı belirtilmiştir (26). Yeack- Jeanne tarafindan yapılan çalışmada (2003), Chang ve Heaman tarafindan yapılan (2005) çalışmalarda ve Wilson ve arkadaşları tarafindan yapilan (2010) çalışmalarda da benzer sonuçlar elde edilmiștir $(11,12,27)$. Bu çalışmada ilk 30 dakika içerisinde emzirmeye başlatılamamasinin nedeninin hastanede yapilan rutin uygulamalara bağlı olduğu düşünülmektedir.

Çalışmada, bebeklerin emmeye ait refleksler açısından karşılaştırıldığında iki grup arasinda istatistiksel olarak anlamlı bir fark bulunmamaktadır. Radzyminski'nin (2003) yaptığı çalışmada, epidural anestezi alan ve almayan grupta aktif emme ve arama refleksi varlığ1 açısından anlamlı bir fark ortaya konulmamıştır (8). Çalışma bulgularının aksine yapılan başka bir araștırmada epidural ile doğum yapan kadınlarda, bebeklerinde memeyi tutma problemi ve emme güçlüğü bildirme oranının yüksek olduğu belirtilmiştir (28).

Literatüre göre bebeğin etkin emdiğini gösteren belirtilerden biri de bebeğin şakaklarında ve kulaklarında kımıldama olmasıdır. Çalışmada, iki grup arasinda 6 . ve 12 . saatte yapilan gözlemlerde fark bulunmazken, 24. saatte emme sırasında bebeğin şakaklarında hareket olma durumunun anestezisiz olanlarda daha yüksek olduğu bulunmuştur. Emzirme sırasında bu belirtinin gözlemlenebilmesi için süt miktarının artmış olması gerekmektedir. 24 saatteki ölçümde iki grup ara- 
sindaki farkin epidural anestezi grubunda süt salınımındaki gecikmeye bağlı olduğu düşünülmektedir.

Bebeğin uzun-yavaş emmesi süt aldığının önemli bir işaretidir. Bu çalışmada, 6 ., 12., 24. saatlerde uzun- yavaş emen bebeklerin oraninin, epidural uygulanmayan grupta yüksek olduğu tespit edilmiştir. Süt miktarı artıp bebeğin ağz1 süt ile doldukça bebeğin emmesi derinleşmekte ve temposu yavaşlamaktadır. Epidural uygulanan grupta uzun-yavaş emen bebeklerin sayısının daha az olmasinin epidural anestezi grubunda süt salınımindaki gecikmeye bağlı olduğu düşünülmektedir. Literatürde ise epidural uygulanan ve uygulanmayan annelerin bebeklerinin emme hareketlerini karşılaştıran bir çalışmaya rastlanmamıştır.

Süt inme refleksinin değerlendirilebilmesi için süt salınımı belirtilerinin gözlenmesi ve takip edilmesi gerekmektedir. Çalışmamızda iki grup arasında 6., 12. ve 24 . saatlerdeki süt salınımı belirtileri açısından istatistiksel olarak anlamlı bir fark görülmemektedir. Literatürde ise epidural uygulanan ve uygulanmayan annelerin süt inme belirtilerini karşılaştıran bir çalışmaya rastlanmamıştır.

Çalışmada 6., 12. ve 24. saatlerdeki değerlendirmelerde LATCH puanları açsından iki grup arasında fark bulunmamıştır. Bu konuda yapılan son çalışmaların sonuçları bu çalışma ile benzerlik göstermektedir. Chang ve Heaman'in (2002) epidural anestezinin etkili emzirme üzerine etkisini incelediği çalışmada LATCH puanlama sistemi kullanılarak yenidoğanların emzirme davranışı değerlendirilmiş, epidural alan ve almayan grup arasinda istatsitiksel olarak önemli bir fark olmadığ1 ortaya konmuştur (12). Reid ve Ly'in (2001) ve Halpern'nin (1999) yaptığı çalışmalarda da benzer sonuçlar ortaya konulmuştur $(29,30)$. Bu çalışmanın aksine Baumgarder ve ark. (6). tarafindan yapilan araştırmada doğumda kullanılan epidural anestezinin ilk 24 saatteki emzirmeyi negatif etkilediği ortaya konmuştur. Wiklund ve arkadaşlarının yaptıkları çalışmada epidural anestezi ile doğum yapan grupta doğum sonrası ilk 4 saatte yenidoğanların emme oranlarının düşük olduğu ve daha yüksek oranda yapay gida aldığ1 tespit edilmiştir (31). Sonucun bu çalışmayla uyumlu olmamasının sebebinin farklı ölçüm aracı kullanımına ve farklı dozda epidural kullanımına bağlı olabileceği düşünülmektedir.

Çalışmada her iki grupta da meme ucu problemlerinin ilk 6. saatte başlamış olması dikkat çekmektedir. Bu durumun annelerin primipar olmasindan kaynaklandığı düşünülmektedir. İki grup arasinda meme ucu problemleri karşılaştırıldığında; meme başında kızarıklık olma açısından 6., 12. ve 24. saatlerde farklılik bulunmazken, meme ucunda ağr1 12. ve 24. saatlerde epidural grubunda istatistiksel olarak önemli oranda yüksek bulunmuştur. Konu ile ilgili yapılan bir çalışmada, meme ucu problemleri açısından anestezisiz doğum yapan ve epidural anestezi ile doğum yapan gruplar arasinda istatistiksel olarak önemli bir fark olmadığı bulunmuştur (12). Bu çalışmada, meme ucunda ağrı ve çatlak şikayetinin epidural grubunda fazla olmasinin nedeninin, epidural anestezi grubunda "sütüm yok, sütüm az" şeklindeki şikayetin yaygın olmasından dolayı süt sağma makinesinin kullanımının yüksek olmasına bağlı olduğu düşünülmektedir.

Çalışmada annelerin bebekleri için sütlerini yeterli görme durumu açısından iki grup arasında anlamlı bir fark bu- lunamamıstır. Epidural grupta bulunan annelerin büyük çoğunluğunun sütün azlığından şikayet etmesi önemlidir. Bu çalışmaya benzer şekilde, Volvamen ve ark. (7). tarafindan yapılan araştırmada, epidural grupta bulunan annelerin sütlerini yeterli görmedikleri için mama ile beslemeye geçtikleri belirlenmiştir. Sütüm yok şikâyetinin epidural grupta sık sı tekrarlandığının da altını çizmişlerdir. Doğumda kullanılan epidural anestezi oksitosin salınımını engellemektedir $(13,14)$. Sütün gelmesi için oksitosin aktivasyonu gerekliliği göz önüne al1nırsa, bu durumun süt salınımını geciktirdiği düşünülebilir.

\section{SONUÇ VE ÖNERILER}

Araştırmada LATCH skorları ve etkili emzirmenin belirtileri açısından gruplar arasında önemli bir farklılık olmadığ1 belirlenmiştir. Sonuçlara göre, epidural anestezinin bebeğin emme reflekslerini olumsuz etkilemediği, fakat epidural uygulanan grupta "sütüm yok" şikayetinin yaygin olduğu ve epidural kullanımının süt salınımını geciktirdiği düşünülmektedir.

Çalışmaya göre antenatal ve postnatal dönemde ailelerin anne sütü hakkında bilgilendirilmesi ve anne sütü ile beslenme konusunda farkındalık kazandırılması, doğumdan sonra ilk $30 \mathrm{da}-$ kika içinde emzirmenin başlatılması, postpartum ilk 24 saatte emzirme problemlerinin ortadan kaldirılması için tüm annelerin sağlık personeli tarafindan desteklenmesi, epidural anestezinin süt inme refleksi üzerine etkisinin daha büyük örneklem grubunda araştırılması ve araştırmanın daha büyük örneklem grubunda yapılması önerilmektedir. 


\section{KAYNAKLAR}

1. Giray H. Anne sütü ile beslenme. STED 2004;13:12-15.

2. Hacettepe Üniversitesi Nüfus Etütleri Enstitüsü, "2013 Türkiye Nüfus ve Sağlık Araştırması" Hacettepe Üniversitesi Nüfus Etütleri Enstitüsü, T.C Kalkınma Bakanlığı ve TÜBİTAK, Ankara, Türkiye, 2014.

3. Taşkın L. Doğum ve kadın sağlığı hemşireliği, 7.Bask1, Ankara: Sistem Ofset Matbaacilik, 2009.p. 493-49.

4. Dewey KG, Nommsen-Rivers LA, Heinig MJ, et.al. Risk factors for suboptimal infant breastfeeding behavior, delayed onset of lactation, and excess neonatal weight loss. Pediatrics 2003;112:607-619.

5. Tolvaldsen S, Roberts CL, Simpson JM, et.al. Intrapartum epidural analgesia and breastfeeding: a prospective cohort study. Int Breastfeed J 2006;1:24.

6. Baumgarder DJ, Muebl P, Fischer M, et.al. Effect of labor epidural anesthesia on breastfeeding of healthy full-term newborns delivered vaginally. J Am Board Fam Pract 2003;16:7-13.

7. Volmanen P, Valenne J, Alahuhtas S. Breast-feeding problems after epidural analgesia for labour: retrospective cohort study of pain, obstetrical procedures and breasfeeding practices. Int $\mathrm{J}$ Obstet Anesth 2004;13:23-9.

8. Randzyminski S. The effect of ultra low dose epidural analgesia on newborn breastfeeding behabiours. J Obstet Neonatal Nurs 2003;32:322-31.

9. Beilin Y, Bodian CA, Weiser J, et.al., Effect of labor epidural analgesia with and without fentantly on infant breastfeeding. Anesthesiology 2005;103:1211-7.

10. Loftus JR, Hill H, Cohen SE. Placental transfer and neonatal effects of epidural sufentanil and fentanyl administered with bupivacaine during labor Anesthesiology. 1995;83:300-8.
11. Yeack JL. The effect of epidural agents in initiation of breastfeeding on the newborn infant. Masters Abstracts International. 2001;40:06-85

12. Chang ZM, Heaman MI. Epidural anal gesia during labor and delivery: effects on the initiation and continuation of effective breastfeeding. J Hum Lact 2005;21: 305-14.

13. Rahm VA, Hallgren A, Högberg H, et.al. Plasma oxytocin levels in women during labor with or without epidural analgesia: a prospective study. Acta Obstet Gynecol Scand 2002;81:1033-9.

14. Goodfellow CF, Hull MG, Swaab DF, et.al. Oxytocin deficiency at delivery with epidural analgesia._Br J Obstet Gynaecol 1983;90:214-9.

15. Emzirme danışmanlığı el kitabı, Ankara: T.C Sağlık Bakanlığı Ana Çocuk Sağlığı ve Aile Planlaması Genel Müdürlüğ̈̈;2000;622.

16. Shealy KR, Li R, Benton-Davis S, et.al. The CDC guide to breastfeeding Interventions.http://www.cdc.gov/breastfeeding/ pdf/breastfeeding_interventions.pdf Erişim tarihi: 02.05.2010

17. Çavuşoğlu H. Çocuk sağlığı hemşireliğiCilt II, (6.Bask1), Ankara: Sistem Ofset, 2002;39-56.

18. Gür E. Anne sütü ile besleme. Türk Ped Arş 2007;42:11-5.

19. Jensen D, Wallace S, Kelsay P. LATCH: A breastfeeding charting system and documentation tool. JOGNN 1994;23: 27-32.

20. Yenal K, Okumuş H. LATCH emzirme tanılama aracının güvenirliğini inceleyen bir çalışma, Hemsire Arast Gelist Derg 2003;5:38-44.

21. Kumar SP, Mooney R, Wieser LJ. The LATCH scoring system and prediction duration, J Hum Lact 2006;22:391-397.
22. Zuppa AA, Alighieri G, Riccardi R, Cavani M, Lafisco A, Cota F, Romagnol $\mathrm{C}$, Epidural analgesia, neonatal care and breastfeeding. Italian Journal of Pediatrics 2014;40:82-87.

23. Leighton BL, Halpern SH. Epidural analgesia: effects on labor progress and maternal and neonatal outcome. Semin Perinatol 2002;26:122-35.

24. Kösüs A, Kösüs N, Çapar M. Nullipar gebelerde sürekli epidural analjezinin maternal ve fetal sonuçları. J Gynecol Obst 2007;17:436-441.

25. Soncini E, Grignaffini A, Anfuso S, et.al. Epidural analgesia during labour: maternal, fetal and neonatal aspects. Minerva Ginecol 2003;55:263-9.

26. Mauri PA, Contini NNG,Giliberti S, Barretta F, Consonni D, Negri M, Benedetto ID, Intrapartum Epidural Analgesia and Onset of Lactation: A Prospective Study in an Italian Birth Centre. Maternal and Child Health Journal 2015; 9:511518.

27. Wilson MJA, MacArthur C, Cooper GM, et.al. Epidural analgesia and breastfeeding: a randomised controlled trial of epidural techniques with and without fentanyl and a non-epidural comparison group, Anaesthesia 2010;65:145-153.

28. Kjerulff K, Zhu J,Velott D, AlligoodPercoco N, Martin AJ. Impaired breastfeeding and epidural analgesia: Is there an association?

https://apha.confex.com/apha/141am/ webprogram/Paper286546.html, Erişim tarihi: 10.08 .2015

29. Reid SJ, Ly D. Does ultra-low dose labor epidural analgesia influence early breastfeeding? Anesthesiology 2001;94(Ek 1A):21.

30. Halpern S, Levine T, Wilson D, et. al. Effect of labor analgesia on breastfeeding success. Birth 1999;26:83-88.

31. Wiklund I, Norman M, Uvnas-Moberg $\mathrm{K}$, et. al. Epidural analgesia: Breastfeeding success and related factors. Midwifery 2009;25:31-38. 